ARTICLE

https://doi.org/10.1057/s41599-018-0211-8

\title{
The effects of prestige on collective performance and information flow in a strictly hierarchical institution
}

\author{
Matt Offord (1,2,3, Roger Gill ${ }^{1}$ \& Jeremy Kendal ${ }^{2,3}$
}

\begin{abstract}
Institutions such as the military aim to respond efficiently to complex logistical challenges using a strictly hierarchical structure, where leaders are assigned a rank by senior colleagues and team members are trained to obey leader commands. Anthropologists have observed that leadership status outside of these top-down hierarchical institutions is often affected by the attribution of prestige by non-leaders. Here we show that even in the strictly hierarchical institutional context of the Royal Navy, informal prestige networks play a functional role in leadership efficacy and group-level dynamics. Specifically, a team leader's informal prestige is a far stronger predictor of team performance and rate of information transmission during training exercises at sea than their formal rank. We find that the more decentralised the prestige network the more efficient it is for disseminating information. The implications of our findings for traditional conceptions of leadership in hierarchical institutions and the effects of prestige on group-level behaviour are discussed.
\end{abstract}

\footnotetext{
${ }^{1}$ Durham University Business School, Durham, UK. ${ }^{2}$ Durham University Department of Anthropology, Durham, UK. ${ }^{3}$ Centre for the Coevolution of Biology and Culture, Durham, UK. Correspondence and requests for materials should be addressed to M.O. (email: matt.offord@yahoo.co.uk)
} 


\section{Introduction}

S trictly hierarchical institutions such as the military rely on a formal leadership structure to coordinate and distribute group activity in response to complex social and environmental challenges. Here leadership is conferred by top-down mechanisms and leadership style is dominance-based, characterised by assertion, control, decisiveness, and assurance in achieving goals (Kakkar and Sivanathan, 2017; Henrich et al., 2015). An evolutionary framework approaches leadership in a rather different way, a way which is rather more critical of the need for leadership. Boehm $(1993,2001)$ asserts that humans are inclined to adopt tactics employed to tolerate leaders only to the degree that their direction benefits the group. For example, 'levelling' behaviours can be used to undermine directives from incompetent leaders (Offord et al., 2016) Evolutionary leadership theory (ELT) asserts that group coordination problems are solved by the coevolution of leader and follower strategies (Van Vugt and Ahuja, 2010; Van Vugt, 2009; Van Vugt et al., 2008; King et al., 2009). Top-down formal leadership models often ignore the role of informal leadership through the mechanism of prestige.

Social psychology has long suggested that conferring of prestige is an important strategy affecting leadership (Asch, 1948), yet this has been largely neglected in traditional leadership studies. How do leaders acquire prestige? von Rueden et al. (2014) in their study of small scale societies in Bolivia discovered that physical cues in addition to trust and kin group size were predictors of leadership emergence. Until the 1940's leadership studies largely focused on traits which were mainly considered masculine in addition to intelligence. This overlaps somewhat with this study (Ibid.) but ignores the elements of trust and social capital. von Rueden et al. (2014) also observe that the leaders they studied were unlikely to claim greater reward for taking up the position as a leader. This differs significantly from contemporary western views of leadership and supports the view that humans are ambivalent about leadership and will not tolerate leaders who attempt to gain disproportionately from their position (Van Vugt and Ahuja, 2010; Van Vugt, 2009; Boehm, 2001). Both dominance and prestige are viable social strategies contingent on the specific context and personalities involved (Cheng et al., 2013). Additionally, methods to determine prestige (such as assessing the extent to which high status persons are gazed at) could equally be measuring dominance (Ibid.). Since dominance and prestige are both viable but distinct (Ibid.), methodologies to capture prestige scores must not be confounded by dominance. Cheng et al. (2013) address this by using peer assessment of prestige and dominance. In our study, likewise, we use a peer assessment of prestige.

Chudek et al. (2012) claims that prestige 'refers to learners' preference for inferring cultural information from whoever receives more attention and/or freely conferred deference from other learners'. Cultural information is derived from high-prestige actors and these actors receive disproportional attention. When there is a significant cost to overt assertion, leadership strategies may be more reliant on prestige than on dominance, whereupon the confirmation of status to certain individuals is based on the attention that he or she receives (Barkow et al., 1975; Grabo and van Vugt, 2016; Henrich and Gil-White, 2001; Van Vugt et al., 2008). For followers, prestige in a specialised field of expertise can make potential leaders a reliable source for learned information over, for instance, simple independent trial-and-error learning (Henrich and Gil-White, 2001). 'Info-copying' prestigious individuals, where followers are strongly influenced to the point of adopting similar language to a prestigious individual, effectively trades the cheap acquisition of useful social information for the costs of paying deference, and is one example of how leadership based on prestige may emerge in groups (Henrich et al., 2015;
Henrich and Gil-White, 2001; Van Vugt and Ahuja, 2010). Learning from trusted models can be generalised beyond the prestigious individual's own domain of expertise, particularly when information quality is opaque to the learner, resulting in convergence of within-group knowledge, skills, values and beliefs (Henrich and Boyd, 1998).

Henrich et al. (2015) demonstrate that prestige aids the cultural emergence of cooperation, a genetic link in the selection of prosocial leaders in small groups; and status differences are based on cultural transmission in large groups. They use the example of the 'Big Man', a explanatory case of prestige in action (Ibid.). Big Men do not usually inherit power, nor do they use coercion. They are therefore reliant on the power of prestige to effectively manage information goods(Ibid.). Prestigious individuals are able to marshal resources which generate power without resorting to coercion. Consequently, prestige may take the form of structural factors determined by where an individual, group or even a nation is placed within a network (Smith et al., 2014; McClurg and Lazer, 2014).

This approach is radically different to traditional views of leadership which place leaders as the sole focus of study without the need to study followers or leader-follower interaction. This paradigm began to decline after Ralph Stogdill's review of leadership traits in 1948 (Stogdill, 1948) that led to a realisation that it would be very difficult to narrow down a set of measurable leader traits that might explain group performance (Stogdill, 1948; Antonakis et al., 2012). This led to a post-heroic era of leadership studies that acknowledged the prior romanticised view of leadership (Bligh and Schyns, 2007; Bligh et al., 2011; Meindl, 1995; Edwards, 2014) and explored the integration of leaders' and followers' traits and behaviours with situational parameters (Antonakis et al., 2012; Dinh and Lord, 2012; Zaccaro, 2007; Bligh and Schyns, 2007). Nonetheless, an heroic outlook still prevails in leadership studies situated in modern western contexts while, by contrast, anthropologists have reported that many contemporary peoples exhibit egalitarian and distributed leadership, considering leadership as a collective social process (Bolden, 2011; Edwards, 2014; Bird and Bliege Bird, 2010; Boehm, 2001). Our theoretical framework departs from the individualistic view of leaders with the leader-follower relationship expressed as top-down control. This framework is also followed by network and complexity studies such as (Helbing et al., 2015) who demonstrate that topdown control often fails to achieve its intended results in complex networks. Cross-disciplinary studies of networks, complexity science and applied mathematics demonstrate the power of bottom-up and self-organised activity to influence social networks (e.g., Helbing et al., 2015; Jalili and Perc, 2017).

The post-heroic paradigm of leadership studies includes a focus on dynamic relations between actors and so has used social network analysis to consider prestige and related concepts of positional leverage and power (Balkundi and Kilduff, 2005; Karp, 2013; Larsson and Lundholm, 2010). For instance, actor centrality, defined by the number of ties transmitted and received by an actor, has been considered as a proxy for power potential (Brass and Burkhardt, 1993), and studies have found that centrality correlates with perceived charisma and group performance (Balkundi et al., 2011; Mehra et al., 2006; Sparrowe et al., 2001; Bono and Anderson, 2005). Similarly, network science has provided compelling evidence that centrality is positively correlated with the ability to disseminate information, including information cascades (Jalili and Perc, 2017) Centrality contrasts with our measure of prestige which is defined only by the number of ties an actor receives. Ego-centred networks, comparing individuals' networks rather than a leader's position within the whole network, have been used to address the role of prestige (Parker et al., 
2013; Hoppe and Reinelt, 2010; Balkundi and Kilduff, 2005). For example, Parker et al. (2013) discovered that academic leadership is positively affected by large social networks. (Henrich and GilWhite, 2001) defines prestige as 'freely conferred deference' which is mathematically different to the notion of centrality used by leadership scholars (e.g., Balkundi et al., 2011) which describes structural position and does not discriminate between relationships which are freely conferred or reciprocal. This characterisation of prestige is missing from traditional leadership studies. Our study is the first that we are aware of to combine anthropological approaches to prestige with traditional leadership literature and to apply it in a strictly hierarchical context. Kakkar and Sivanathan (2017) take the step of applying the argument about dominance versus prestige to modern politics, finding that dominance, rather than prestige-based leadership, is positively correlated with economic uncertainty. Given this, we might predict that dominance-based leadership should predominate in military institutions which are commonly act in highly uncertain environments. However that study does not consider the uncertainty of a military environment which should, by their findings increase the level of dominance (Ibid.).

In our study, we examine the role of leader prestige in the Royal Navy (RN), an ostensibly hierarchical institution, during complex training tasks characterised by highly uncertain environments. The functional structure on $\mathrm{RN}$ warships is a series of nested hierarchies typical of Industrial Age organisations. Although all individuals report ultimately to the Commanding Officer, they are arranged in Divisions, based on specialisation (e.g., the Marine Engineering Department) (see Fig. 1). Individuals report to functional supervisors (usually in the same specialisation), who report to Senior Rates, who report to Heads of Department. Only at this point is information shared with that of other departments amongst the Command Team (comprising the Heads of Department and the Commanding Officer). This has the effect of creating specialised channels for each kind of activity which cycles information from the Commanding Officer to the lowest levels in the hierarchy. Each task is allocated a leader at the lowest level required to achieve the task. Therefore simple tasks are led by supervisors in the specific specialisation required (e.g., a seaman supervisor for a seamanship task, such as launching a boat). More complex tasks require higher-level supervisors with

\section{Typical power structures on Royal Naval warships}

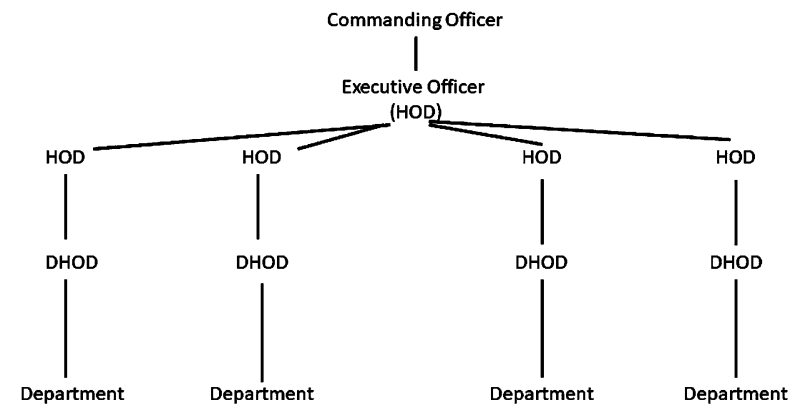

$\mathrm{HOD}=$ Head of Department

DHOD $=$ Deputy Head of Department

Fig. 1 The diagram shows how RN warship are split into divisions which act as separate information conduits up the chain of command The Divisional System separates the pastoral care and functional control of sailors into departments defined by occupational specialisation (e.g., engineers or communication specialists). Within each department, junior sailors are supervised by Leading Hands, who are managed by Senior Rates and Officers. The department is led by DHODs and HODs, who report to the Commanding Officer via the senior HOD, the Executive Officer whole-ship tasks being led either by the Commanding Officer or Executive Officer. Reporting of sub-tasks, in this case, is usually accomplished through the chain of command for each Division, so activity is nearly always achieved through specialised teams.

The $\mathrm{RN}$ is particularly interesting precisely because formal leader and follower roles are strongly pre-defined principally for the purpose of optimising coordinated group-level exercise outcomes. Bloch (2008) described such roles as the transcendental social, referring to imagined public roles or positions that continue to exist beyond the term of the role-holder. In strongly hierarchical institutions such as the $\mathrm{RN}$, prestige and social behaviour is expected to be strongly influenced by the transcendental social, defined by rank, resulting in efficient group-level outcomes. Our study challenges this assertion by examining the degree to which differential symbolic capital and prestige accrued by role-holders affects social behaviour and group outcomes. Our measures of informal prestige are derived from Offord et al (2016)'s qualitative focus group study that proposed a leadership model in which crew might confer prestige via two modes of interaction, advice and participation, resolved into four dimensions: seeking credible professional and personal advice plus engaging in sports and social participation. In Offord et al. (2016) we used qualitative methods to identify two modes of interaction that affect prestige-development. Although advice networks fit neatly with the 'information goods' approach (Henrich et al., 2015) the notion of interaction via sports or social events has a less obvious connection. Although the use of participation networks is not derived directly from 'information goods' theory, we allow for the possibility that trust built up through participation could affect leader prestige and cohesion to influence team performance. We needed to find out whether the trust built up through participation would act as a modifying influence on team performance and the flow of information within groups.

First, we report empirical network analyses, examining the effect of group-leader prestige on team performance and information transmission, before using computer simulation to explore the possible effects of informal prestige network structure on the rate of information transmission through the network. We demonstrate that, far from relying on traditional top-down leadership, naval teams use distributed leadership enabled through a spread of the prestige network operating at all levels of the organisation. We suggest that the evolution of leadership from early egalitarian roots to a modern hierarchical (command and control) structure is too simplistic a model. In fact, the formal hierarchy is supplemented by an informal prestige structure which is often ignored and yet is vital for group coordination.

\section{Empirical analysis}

We collected interaction network data for eight crews from Mine Counter Measures Vessels (MCMV) and two crews from an Offshore Patrol Vessel (OPV). Measures of team-leader interaction and rank were correlated against (i) team performance, measured during training exercises performed on the MCMVs, and (ii) information transmission during complex training exercises on the OPV. Practical limitations restricted our collection of team performance data to the MCMVs and information transmission data to the OPV; possible effects of vessel type are considered in the discussion. An MCMV training period is four weeks, generating approximately 800 assessment reports in total, but for various practical reasons information transmission data could not be collected. The OPV training programme is only one week and did not generate a statistically viable sample of performance assessments but did allow the collection of detailed information transmission data. 


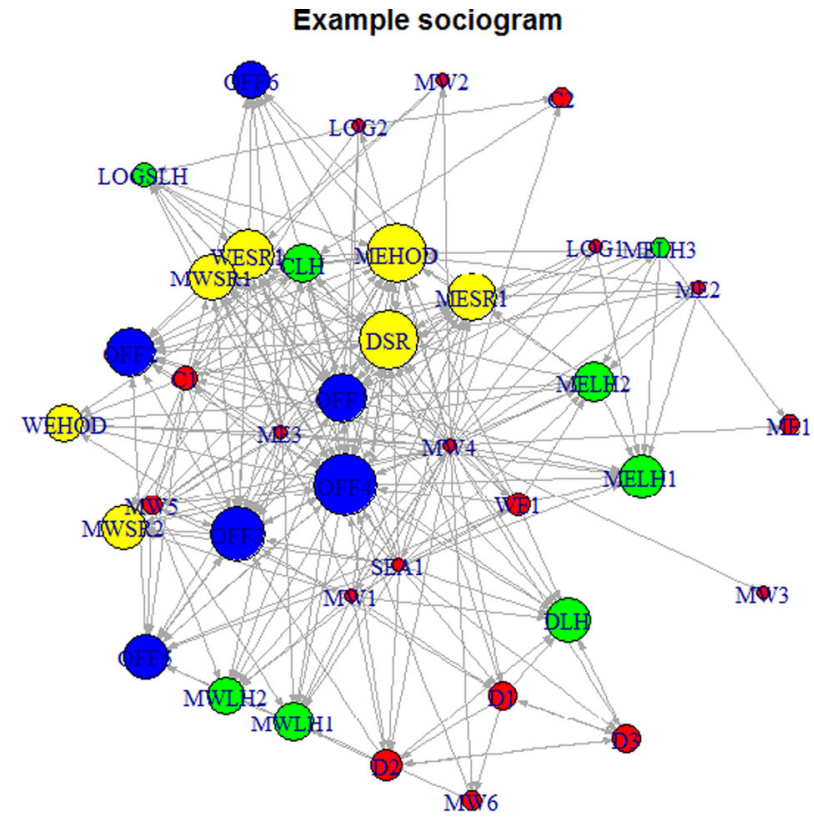

Fig. 2 A typical social network from an RN warship illustrating levels of prestige among crew members A sociogram from an MCMV constructed from a hypothetical sociomatrix of typical prestige scores. The colours of the nodes indicate rank. From the highest to the lowest ranks the nodes are coloured: blue = officers; yellow = senior rates; green = leading hands; red $=$ able rates. The size of the node is proportional to its prestige

Data were collected from eight MCMVs comprising $323 \mathrm{crew}$ members in totalin the vicinity of the River Clyde, Scotland, in 2012, and from two crews (a total of $78 \mathrm{crew}$ ) from an OPV located in the Falkland Islands in 2015. The crew (called a 'Ship's Company') are very similar in make-up and size (around 40 (range $=39-43$, mode $=39$ ) ) across the two types of vessel, although the MCMV crew is permanent while the OPV changes crew every six months. In total 401 sailors participated in the study, creating 4 sociograms per ship, that is 40 sociograms in total.The average age of the participants was 32.4 years and the Ships' Companies were predominately male (12\% female). All personnel volunteered to participate fully, so a 100 percent return of the data was achieved.

Prestige network analysis. After piloting a questionnaire on a separate MCMV (performed in 2012), we collected interaction network information on all vessels by administering a questionnaire that identified a list of the ship's company and asked the volunteer to mark against relevant crew in response to one of the following (each question on a separate page):

1. Do you go to this person for professional advice?

2. Do you go to this person for personal advice?

3. Do you play sport with this person?

4. Do you socialise with this person?

From these data, we constructed prestige networks, or directed graphs, based on each of the four types of interaction (professional advice, personal advice, sport, socialising). For each type of interaction, our measure of prestige for each actor, $i$, is given by

$$
P_{D}^{\prime}(i)=\frac{d(i)}{g-1}
$$

This is the number of edges (or ties) an actor receives, or indegree, $d(i)$, standardised by the possible number of edges, $g-1$. This measure is adapted from Wasserman and Faust (1994, p. 179)'s measure of centrality, which includes both the number of ties transmitted and received by an actor. The use of directed graphs for advice networks is straightforward since requests for advice are directed at specific individuals and one-way. Although the responses to the participation questions (e.g., do you play sport with this person?) are directed, they are also commonly reciprocal in practice. This suggests a framework other than that of freely conferred prestige (Henrich and Gil-White, 2001) and therefore compares the 'information goods' theory with other means of accumulating prestige. An example sociogram is shown in Fig. 2.

Sociograms were obtained from $8 \mathrm{MCMV}$ and $2 \mathrm{OPV}$ warships. These 10 crews contributed a sociogram in each of the four dimensions, totalling 40 network graphs, that is 10 graphs for professional, personal, social and sports prestige. The number of crew was usually 44 , although some vessels had up to 4 extra persons for training. Variation in the number of vertices was accounted for by normalising all network statistics between one and zero. The average density for all 40 sociograms was 0.17 , but was higher for social and professional networks (0.19 and 0.18 respectively). Density was lower for sports networks (0.15) and lowest for personal advice networks (0.14). The average number of edges (or ties) between vertices varied between 223 and 309, with more ties for professional and social networks, a reflection of the density findings. The diameter of all the networks was four, except the professional sociogram with five. This small diameter indicates close-knitted teams. Figure 3 summarises that prestige values for the MCMV and OPV vessels. The within-crew variation of prestige across the eight MCMV crews was larger than across the two OPV crews. Although the relative scores within each sample demonstrate a similar profile, the absolute scores were higher within the MCMV community. MCMV crews

a
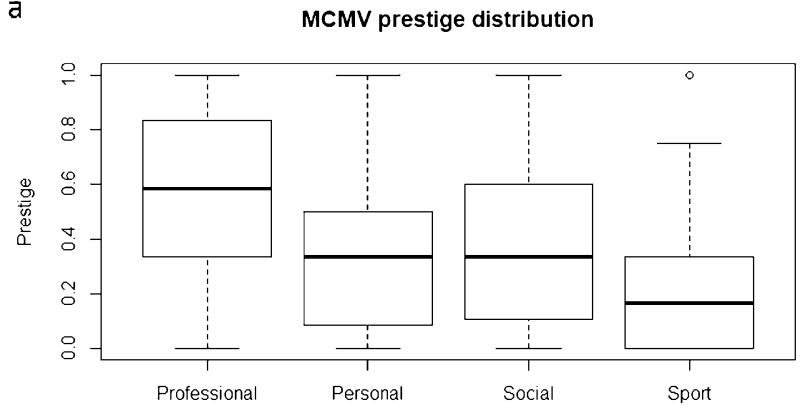

b

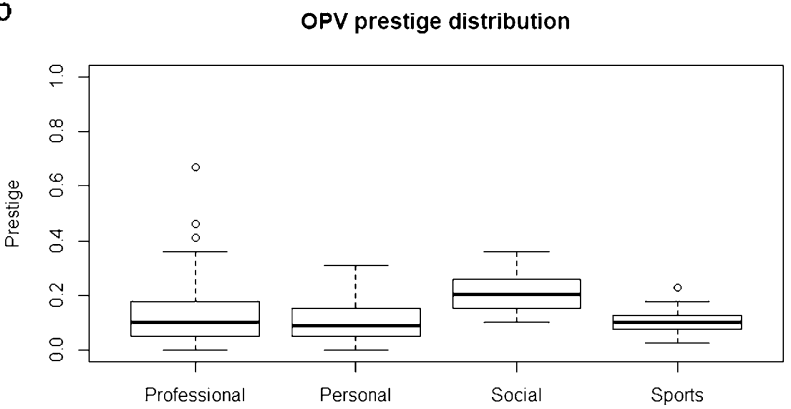

Fig. 3 Sub-Figure A - MCMV Prestige Box Plot Sub-Figure B - OPV Prestige Box Plot. The distribution of prestige among two different classes of warship MCMVs $(n=363)$ and OPVs $(n=78)$ crews, where boxes show data points between the 25th and 75th percentiles, and whiskers show the minimum and maximum values 


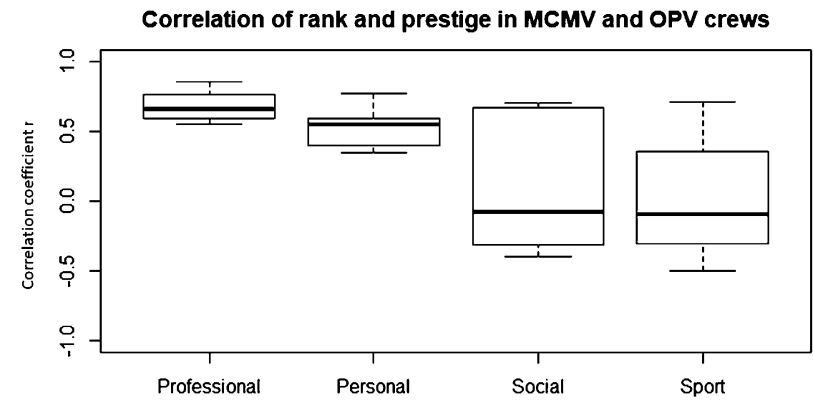

Fig. $4 \mathrm{~A}$ box plot illustrating how formal rank correlates with informal prestige scores. $(n=320)$. The box plots show the median correlation of rank and prestige as a white line. 25th and 75th percentiles appear below and above this line respectively. Minima and maxima are indicated by whiskers and the mean correlation is stated in each box

are largely stable over a period of 2 years, albeit that there is significant change in personnel at any time. OPV crews, on the other hand, only spend 6 months in the Falkland Islands, although they remain together as a unit when operating other vessels in the same class. Although the crew are well known to each other, they have had relatively little time to operate together within that specific environment, and therefore prestige networks are still developing.

We examined the degree to which prestige is conflated with rank, which is a likely status marker. Figure 4 shows that professional advice is highly correlated with rank. This assessment was conducted for the MCMVs but we discovered a similar connection on the OPVs. While we find the highest mean correlation of rank with the professional prestige, it is its mean divergence of $31.5 \%$ which is perhaps surprising. Other prestige categories exhibit lower or even no correlation at all. It is interesting to note that both sporting and social interactions appear heterogeneous with respect to rank.

Team performance. Operational Sea Training took place during several weeks of intensive operations observed by sea-riders. These operations are broken down into so-called serials which range from basic operational skills to firefighting, damage control and complex warfare operations. Each team (e.g., engineering department, seamanship department etc.) completed a number of serials, while some serials involved multiple departments or the whole ship. Each serial was assessed by sea-riders according to a training manual called the Operational Sea Training Guide. We had access to the sea-riders' assessments of team performance over 345 admissible serials carried out across the MCMVs, and note that internal reliability was high (Cronberg's $\alpha=0.904)$. Of the 345 serials, the majority of groups $(n)$ conducted each serial only once each while the remaining groups (16) conducted no more than 2 serials each. We treated each serial to be independent of one another as the considerable variation across serial tasks and environmental conditions was likely to swamp the effect of repeated measures in the minority of teams that contributed more than one serial. We obtained qualitatively similar results using only groups that contributed one serial to the dataset. For each team, the prestige variable for the formal team leader was compared with serial assessment using a logistic regression (carried out using Stata 13 statistical software). Each form of prestige (professional, informal, sport, social) was used as a predictor variable in separate models, in addition to a model that used the mean all four types of prestige as a predictor variable. The assessment data were originally ordinal, taking the following possible levels: 1. Unsatisfactory, 2. Below standard, 3. Satisfactory, 4. Very satisfactory, 5. Good, 6. Very good.

\begin{tabular}{|lcc|}
\hline $\begin{array}{l}\text { Table } 1 \text { Summary of logistic regressions of team } \\
\text { performance and independent variables }\end{array}$ \\
Variable & Odds ratio & $\boldsymbol{p} \geq \chi^{\mathbf{2}}$ \\
\hline Professional prestige & 6.065 & $0.000^{\star \star}$ \\
Personal prestige & 4.814 & $0.000^{\star \star}$ \\
Sports prestige & 2.854 & $0.001^{\star \star}$ \\
Social prestige & 2.616 & $0.005^{\star \star}$ \\
Combined prestige & 12.947 & $0.000^{\star \star}$ \\
Rank & 0.995 & 0.936 \\
\hline${ }^{\star \star} p \leq 0.01(N=345)$ & \\
\hline
\end{tabular}

We transformed these data into a binary response variable because of positive skew in the distribution of scores and some rarely used categories. The cut-off point was the Very Satisfactory assessment, which was designated high, as these were superior assessments. Satisfactory and lower assessments were deemed as a low performance. A logistic regression (see Table 1) revealed that all four types of prestige positively correlated with team performance during Sea Training, with large effect sizes. The combined model, using the mean of the four interaction types as the predictor variable, achieved the largest effect size and also demonstrated the highest goodness-of-fit and best variance statistics.

Table 1 also shows that rank is insignificant in the model. This is primarily due to the wide range of ranks of leaders of the serials we observed. Team cohesion (measured by calculating density) also failed to make a significant contribution to team performance. There was, however, a non-significant cohesion result for all four networks. A full explanation of our treatment of density can be found at Appendix A.

Information transmission. Information transmission data were collected from two different crews on the OPV. The lead author (MO) was present in his capacity as leader of a training team to conduct Operational Sea Training. This role is normal practice and so was unlikely to affect participant behaviour. Dyadic exchanges of information were recorded over the last 48 hours of the crews' training package during which the complexity and intensity of the exercises had increased to the point where information management had become critical to task success. The information transmission data concern two exercises (or serials). The first was a Damage Control Exercise beginning with a simulated air attack performed by two Royal Air Force Typhoon aircraft who flew attack profiles against the Ship. After a period of tracking these aircraft and responding to their actions using Ship's weapons, extensive damage was simulated. The damage took the form of fires, floods, equipment failure and casualties. Information from damage sites within the ship and sensors, monitoring the external environment, was passed from person to person until it reached the Commanding Officer and was added manually to special information boards, called State Boards, on the Bridge.

During the exercise a number of scenarios were simulated throughout the ship by the training team. For example, a compartment would be filled with non-hazardous smoke to simulate a fire. Members of the Ship's Company were observed as they dealt with the incident. Our researcher (MO) witnessed how messages (concerning the incident) were conveyed to the Commanding Officer, recording the exact particulars of the information in a note book and noting how this information was received and how it was noted on the Incident Board on the Bridge, from which the Commanding Officer was briefed. Although it was possible to convey the information by telephone, 
most information was relayed in person to the Bridge via a messenger. $\mathrm{MO}$ was able to follow the messenger to the bridge and record the event as a part of his duties as an observer. Information passed in this way could have been passed successfully, become misunderstood, or completely ignored. Of the 154 observed attempts to pass information all were successfully transmitted or ignored, none were garbled. It is important to note that during periods of intense stress, people experience perception issues, focussing intensely on certain information and filtering out other data. This is why a binary outcome prevailed. An example of this issue is an attempt to pass critical information by a high rank but low prestige individual witnessed by MO. In this case the individual passed the message personally on the Bridge but was completely ignored by the Bridge team who were absorbed in another event to the exclusion of all others. This in itself does not signify that low prestige was the causal effect but demonstrates how messages can fail to be passed. The observations were made during an intense phase of training when communication was occurring throughout the Ship. MO was unable to observe every instance of information transmission in such a frenetic environment. However he was able to draw on his experience and knowledge of the training programme to ensure that mission critical events were observed.

The information types were varied. For example, information may be about the state of a casualty (e.g., the wounds received by a casualty and whether they are stable), progress with fire-fighting (e.g., the fire in a certain location is extinguished). Other information may include the readiness of personnel to conduct damage control (e.g., there are 5 persons at the repair post, dressed and ready for fire-fighting). Further information may come from personnel operating sensors and weapon systems regarding size and disposition of enemy forces. The latter information is extremely dynamic, especially when considering the movement of enemy aircraft; these reports are usually called out on communications networks and transmitted via speakers on the Bridge. Since this information is simply a public broadcast, it was not considered in our observations. However, information gathered below decks concerning damage control (the so-called 'internal battle') was generally passed from person to person and was potentially subject to prestige bias. The urgency of this information was such that communication was always oral. Phone communication is avoided due to potential electrical failures and because it is often impossible for officers to manoeuvre the Ship and answer the telephone at the same time. Nevertheless, phone communications were occasionally used from points within the Ship directly to the Bridge. Most communication was face-to-face, generally passing up the chain of command and remaining within the divisional structure described in our introduction. Often the information would be passed outside of departments if it was deemed to be quicker for example, to pass the information to a trusted individual or an individual who happened to be going to the Bridge. Technical information stayed strictly within technical departments (e.g., electrical or mechanical damage) as it would be incomprehensible outside of specialist departments.

MO witnessed 154 attempts to exchange of information directly and assess the success of attempts to pass operational information from one sailor to another. Information was often passed directly from a person at the scene of the incident who travelled to the Bridge to tell the individual amending the State Board or directly to the Commanding Officer. Logistic regression was used to examine the effect of leader prestige on the success or failure of information transmission.

An attempt to pass information could be clearly observed since the sender would address the receiver loudly and formally, using standard reporting formats. The receiver then repeats the same information to check their understanding, thus it was possible to determine if the information was received or not. In reality, certain individuals were clearly ignored or told their information was not a priority when attempting to pass information. It was straightforward to determine whether or not ignored information was genuinely low priority due to MO's position as an expert trainer. Of the 154 attempts to pass on information, 21 attempts involved the same pair of individuals (13.69\%). We obtained qualitatively similar results using only pairs that contributed one transmission attempt to the dataset.

Our investigation of information transmission showed only the advice networks to be significant: both the personal-advice prestige of the transmitter and receiver predicted successful information transmission, but only the professional-advice prestige of the transmitter predicted successful information transmission. In contrast to the team performance results, rank was significant in univariate regressions with information transmission, but consistent with the team-performance results, including both rank and prestige as fixed variables in a multivariate logistic regression showed that the advice-based prestige, but not rank, correlated with information transmission (see Table 2). Participation networks do not have a significant effect on information transmission and can be excluded from consideration of an "information goods" approach to prestige.

\section{Simulation}

The observed significant effect of informal prestige, but not rank, on information transmission only considered dyadic information transmission events. We used computer simulations (using igraph package on the $\mathrm{R}$ platform (Version 3.3.2.) to extrapolate by exploring, in principle, how rank distribution across a prestige network might affect the rate of information percolation across the entire Ship's Company. To this end, we created a network that was similar in population size and rank distribution to a typical crew from the MCMVs and OPV (see Fig. 5).

To predict the effect of network topology on patterns of information transmission, edge density is held constant across conditions using the mean density of 0.17 recorded across all 10 collected sociograms. The simulated sociograms were based on advice (professional and personal) networks as these have already

\section{Table 2 The effect of rank and prestige on the dissemination of information}

\begin{tabular}{lcl} 
Variable & Coefficient & $\boldsymbol{p} \geq|\mathbf{z}|$ \\
\hline Rank $(\mathrm{T})$ & 1.54 & 0.125 \\
Rank $(\mathrm{R})$ & 0.697 & 0.486 \\
Rank $(\mu)$ & 0.977 & 0.854 \\
Professional prestige $(\mathrm{T})$ & 12.8237 & $0.000^{\star \star}$ \\
Professional prestige (R) & 1.644 & 0.4243 \\
Professional prestige $(\mu)$ & -3.800305 & 0.515 \\
Personal prestige (T) & 17.5282 & $0.000^{\star \star}$ \\
Personal prestige (R) & 10.2621 & $0.000^{\star \star \star}$ \\
Personal prestige ( $\mu)$ & 1.406 & $0.010^{\star}$ \\
Social prestige $(\mathrm{T})$ & 0.21256 & 0.937 \\
Social prestige $(\mathrm{R})$ & -1.1288 & 0.641 \\
Social prestige $(\mu)$ & -39.6043 & 0.773 \\
Sports prestige (T) & 0.8009 & 0.842 \\
Sports prestige (R) & -4.2146 & 0.270 \\
Sports prestige $(\mu)$ & -119.9554 & 0.542 \\
Combined prestige $(\mathrm{T})$ & 9.518 & $0.000^{\star \star}$ \\
Combined prestige $(\mathrm{R})$ & 3.18 & $0.001^{\star \star}$ \\
Combined prestige $(\mu)$ & 41.5538 & $0.000^{\star \star}$ \\
\hline Where $\mu$ indited & &
\end{tabular}

Where $\mu$ indicated the mean value of the transmitter $(T)$ and receiver (R) prestige, and Combined is the effect of average prestige score across all four forms of interaction ${ }^{\star} p \leq 0.05$ $\left.{ }^{\star \star} p \leq 0.01 ; N=154\right)$ 
been shown to have a positive effect on information transmission. We compared four topologically distinct conditions, illustrated in Fig. 6:

i. Random-tie network: edges are randomly distributed, assuming the constant density and population size; i.e., there is no relationship between rank and prestige.

ii. Real-world network: we use one of the collected sociograms that happens to exhibit the mean density and population size.

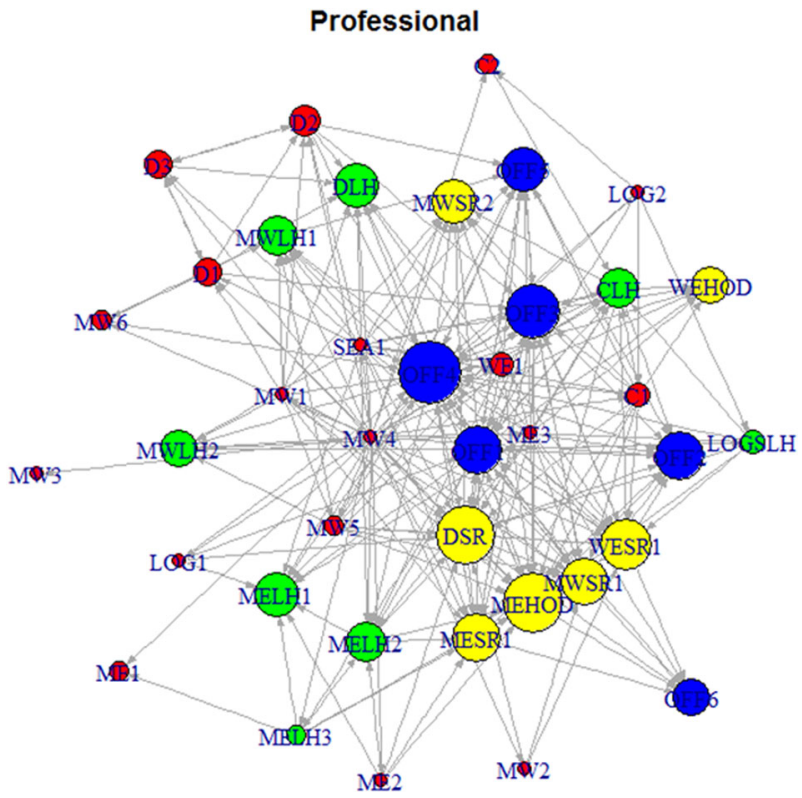

Fig. 5 Model sociogram created for simulation with typical features from our advice-based social network analysis of warships Officers (the highest rank) are shown in blue, followed by Senior Rates (yellow), Leading Hands (green) and Able Rates (red), who are the lowest rank
There is a moderate correlation between rank and prestige such that higher ranks (defined as Officers and Senior Rates (blue and yellow nodes)) tend to have a higher level of prestige.

iii. High-rank, high-prestige network: high-ranking nodes, Officers and Senior Rates (blue and yellow nodes), held higher prestige than low-ranking nodes.

iv. Low-rank, high-prestige network: low-ranking nodes, Leading Hands and Able Rates (green and yellow nodes), held higher prestige than high-ranking nodes.

For each condition, we run 1000 simulations to predict how efficiently information spreads through the network, measured by saturation time (Fig. 7). Each simulation begins by randomly seeding the population with an informed actor selected from the low-ranking 'junior rates' (vertices numbered between 23 and 39), who are the sailors engaged in fighting fires, engaging enemy targets etc, who are the common source of new information. At each time step, informed actors simultaneously attempt to pass information to naive actors. The model is shown at Fig. 7.

We consider two alternative modes by which prestige affects the probability of transmission:

i. Unweighted transmission, where the probability of information passing from an informed individual to a connected neighbour is given by the mean prestige value across the network, $n^{-1} \sum_{i}^{n} P\left(n_{i}\right)$. Thus, the probability of transmission from an informed individual to each connected neighbour is the same.

ii. Prestige-weighted transmission, where the probability of information passing from an informed individual to a connected neighbour is given by the in-degree of the information source node, $P^{\prime}{ }_{D}\left(n_{i}\right)$. In other words, among individuals selected as those to whom a sailor would go for information, transmission is more likely if the potential information source has a high prestige score.
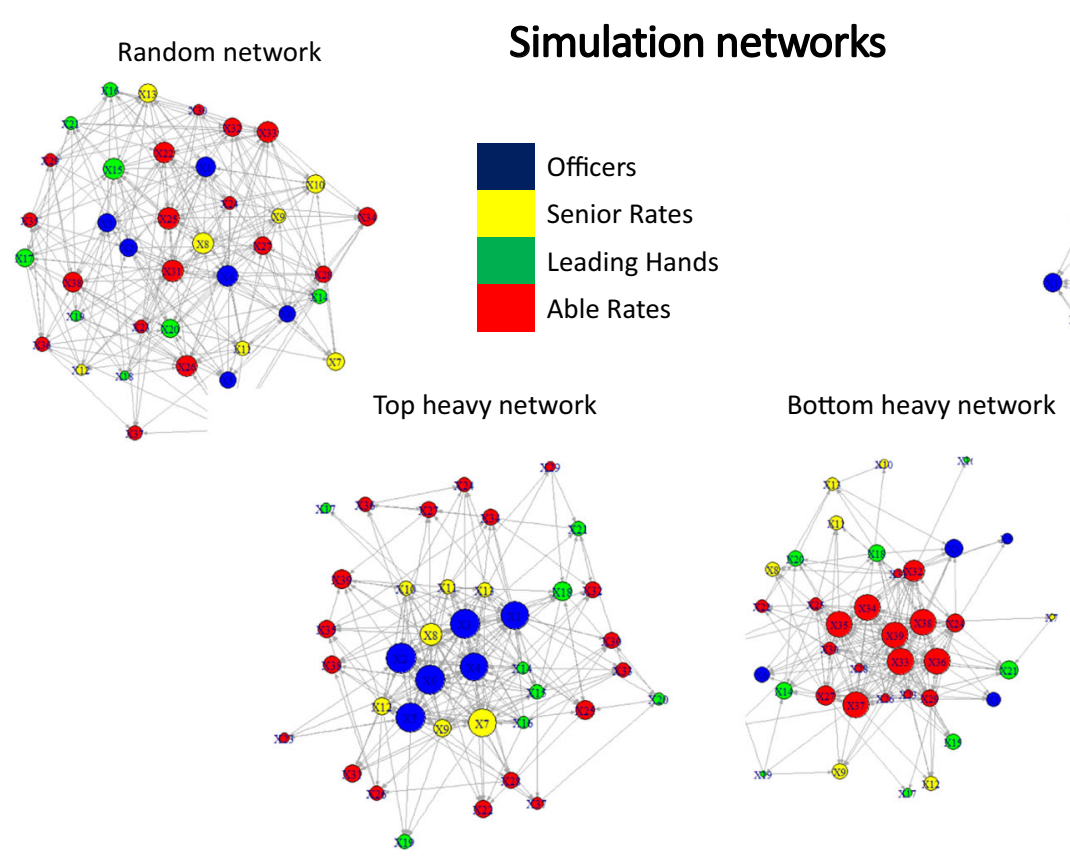

Real world network

etworks

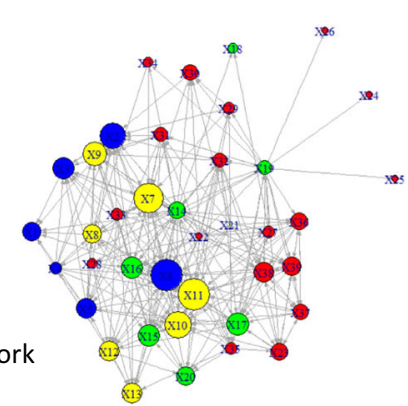

Fig. 6 An illustration of four different types of simulated social networks used to compare information transmission. The 'random' distribution condition shows that higher prestige vertices (shown by larger circles) are represented by all ranks. The 'top heavy' and 'bottom heavy' conditions show large blue or red vertices respectively. The 'real world' condition demonstrates some features of the 'top heavy' network in that the prestigious actors are officers or senior rates. Additionally this network shows greater isolation of the red, lower ranking nodes than any of the other networks 


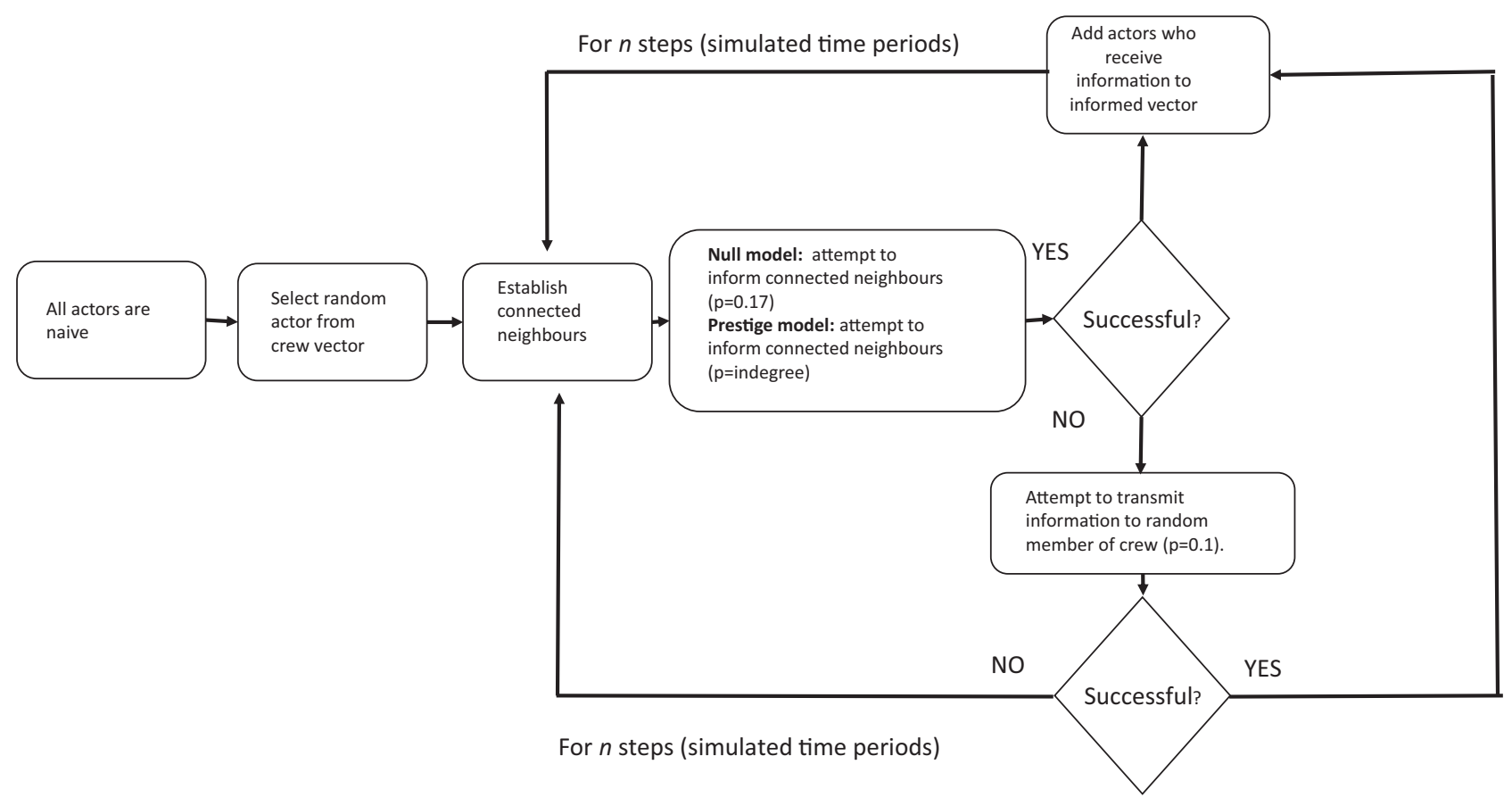

Fig. 7 The production system used to drive information transmission simulations, illustrated using Universal Modelling Language (UML)

Table 3 Results prestige-bias transmission simulations

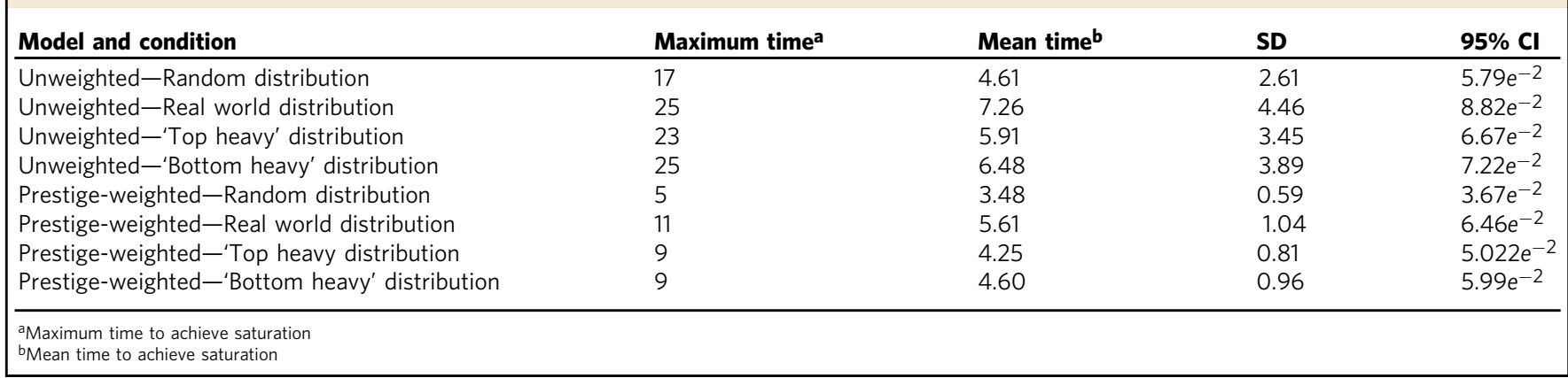

Note that the prestige network edges are directed towards individuals from whom a focal individual would seek information, so information flows in the opposite direction to the directed edges, flowing from prestigious individuals who are sought out for information to those that seek the information. Also, both modes of prestige transmission exhibit the same average probability of transmission across the network, and we do not have empirical data distinguishing which of these two modes was employed by the sailors.

We assume that not all information transmission is a function of the prestige network topology. So if, at each time step, an informed actor does not transmit information via the prestige network, there is a constant probability of non-prestige transmission to a randomly selected recipient, set arbitrarily at 0.1 , so eventually the network will become saturated.

For all four simulated conditions, the unweighted transmission mode typically resulted in a longer saturation time and greater variation in saturation time than the prestige-weighted transmission mode did (see Table 3). Since mean prestige across both modes is identical, it is the variance of prestige among connected actors that explains the differences in efficiency of transmission.

For the non-random network structures (types ii-iv), cliques of prestige featured fast information transmission within the clique but slower transmission to other parts of the network. The random-tie distribution model had enough variance in prestige to create information channels of relatively high prestige individuals combined with a lack of cliques or information bottle-necks. A clique is defined as a subgraph where the actors have all possible ties present among themselves. Informally cliques represent groups within groups who communicate readily within their own group but may not be as well connected outside of the clique. The random-tie network had the lowest number of cliques (5), whereas the real world network had 8 significant cliques. The largest number of cliques (10) was found in both the top and bottom heavy networks.

For both transmission modes (unweighted and prestigeweighted), information spread most efficiently in the random-tie network condition, followed by both the top-heavy and bottomheavy networks, while the real-world network took the longest time to achieve saturation and also exhibited the greatest variation in time to saturation. We also observed that the prestigeweighted mode was considerably more efficient that the unweighted model, this is measured by the number of time steps to achieve saturation. The results are shown in Fig. 8.

\section{Discussion}

Our empirical results suggest that while both advice- and participation-based prestige conferred to group leaders affects 
a
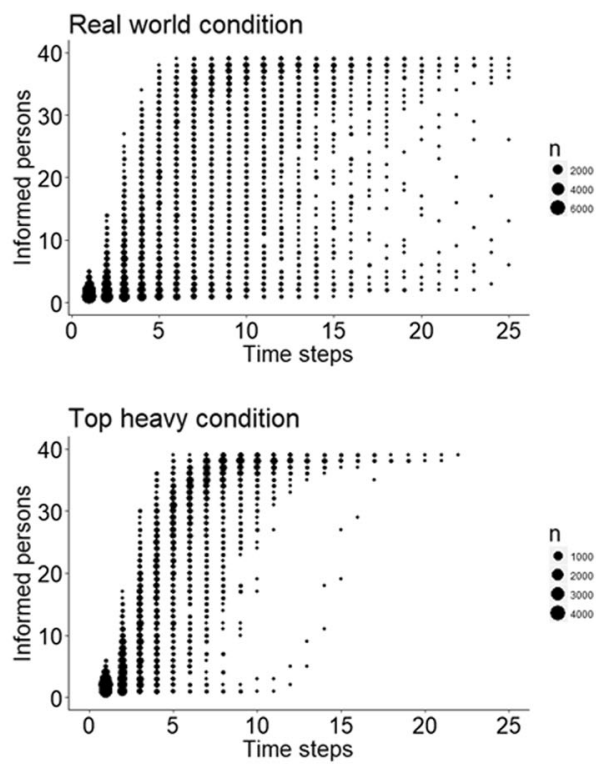

b
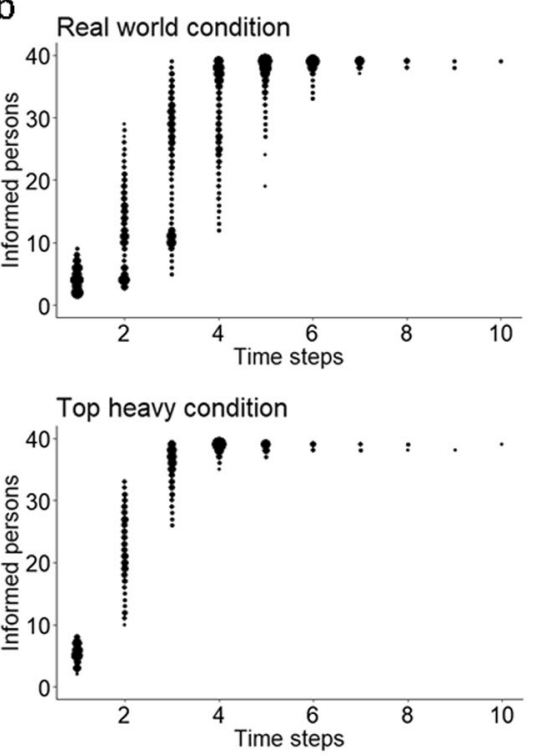
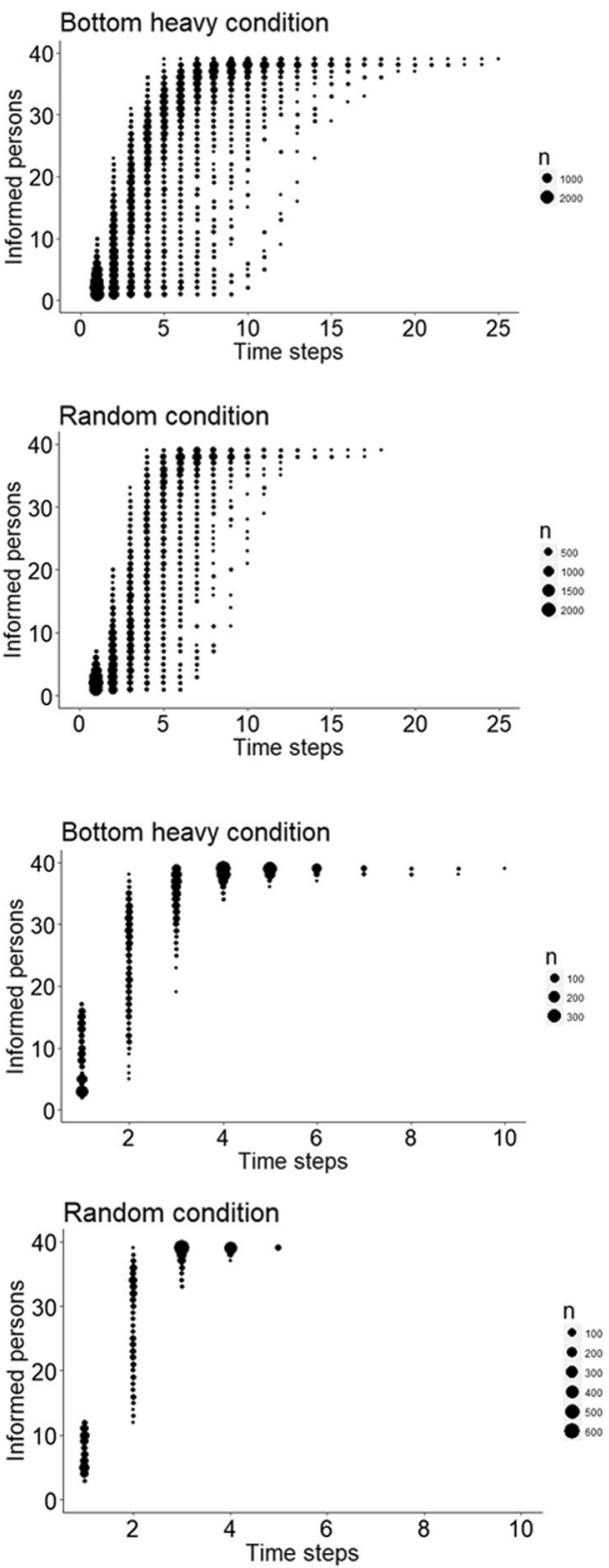

Fig. 8 a The number of informed persons over time in the unweighted mode $\mathbf{b}$ The number of informed persons over time in the prestige-weighted mode. Information spread over time for prestige-weighted and unweighted modes The $n$ value represents the number of possible successful transmissions over 1000 simulations. Consequently the darker and larger circles represent the most likely predictions

group performance, only advice-based prestige positively affects dyadic information transmission. While participation-based prestige was not a part of our 'information goods' mode Henrich and Gil-White (2001) participation networks were retained to observe if they affected the spread of information. In particular, while the personal advice-based prestige of both the sender and the receiver correlate with successful information transmission, only professional advice-based prestige of the sender, and not the the receiver, correlates with successful transmission. Models including both prestige and rank as predictor variables find that, unlike prestige, team-leader rank had no effect either on team performance or on the odds of dyadic information transmission. Extrapolating by simulation to explore the effect of rank distribution on rate of information saturation indicates that the realworld rank distribution is particularly poor at facilitating information transmission compared to either random and top or bottom-heavy distributions of rank with respect to prestige.
While these findings do not show that rank, as a transcendental social construct, is unimportant for the efficient day-to-day running of the Royal Navy, it does suggest that informal prestige can have an important effect on both leadership efficacy and information transmission on operations.

Anthropological theories of prestige as a channel for cultural transmission (e.g., Henrich and Gil-White, 2001) suggest a possible explanation for the finding that prestige in leaders is correlated with higher team performance. Advice networks, particularly professional prestige, seem likely conduits for 'information goods' which are required to coordinate groups. It is likely that prestigious leaders are able to move information around their team efficiently because their prestige confers value on that information. Thus high prestige leads to an 'unthinking acceptance' of an actor as a generally reliable source of information while low-prestige sources are rejected with little consideration of the actual content (Asch, 1948; Greenfield and 
Kuznicki, 1975). Note that prestige bias can be generated through a form of conformist bias in that individuals choose whom to copy on the basis of their observed popularity (i.e., copying the most popular source of advice); however, we cannot rule out the possibility that sailors are independently choosing the same prestigious individual as a source of advice.

Evolutionary studies have shown that adopting a prestige bias in particular domains can confer a fitness advantage (Atkisson et al., 2012; Chudek et al., 2012). While a longitudinal study would be required to assess whether adopting a prestige bias facilitates an individual's promotion prospects, at the group level prestige conferred on leaders correlates with team performance and advice-based prestige correlates with dyadic information transmission.

We found that social and sporting participation networks have a significant effect on group performance. The role of participation would appear to give leaders an opportunity to operate on a level transactional plane with subordinates (Offord et al., 2016). Our findings support the call for more follower-based studies of leadership (e.g., Meindl, 1995) in that follower behaviour is clearly implicated in affecting leader credibility and team performance (Offord et al., 2016). This in turn has much in common with in other post-heroic approaches such as ELT. We discovered that although participation-based prestige affects leader efficacy, high network cohesion or density during participation does not appear to affect team performance. We speculate that the participation networks function in the building of trust and triggering of levelling behaviour towards untrusted leaders (Ibid.).

It is possible that the role of professional and personal credibility in assessing operational information is associated with wisdom and experience. That both sender and receiver prestige is involved in successful transmission indicates a difference between the two advice networks worthy of further explanation. We speculate that trust implied in a personal advice network makes prestige more important for both parties than the transmission of professional advice, which requires only a credible source of information. Individuals sought as a source of personal advice may be considered worth listening to and also effective listeners during team operations.

The empirical results demonstrate that informal advice networks exert a positive effect on accurate dyadic information transmission, but the simulations predict that real-world, hierarchically-ranked, prestige networks lead to a relatively slow spread of information through the ship's company. This reflects an informal observation we made with both crews from HMS Clyde that information appeared to remain within groups of high-prestige individuals, resulting in lower-prestige individuals acquiring less operational information. We had expected highprestige individuals to act as a catalyst in percolating information throughout the network but it appears that they preferentially pass the information to other high-prestige actors This results in a prestige gradient such that difficulty is encountered in moving information from low-prestige to high-prestige individuals. Thus the pathways of information spread may be different paths to those expected from the formal structure.

Widely distributed prestige results in more efficient information transmission than asymmetric distributions do (e.g., 'top heavy' structures) and may have a significant impact on teamwork because prestigious individuals who are not formal leaders facilitate useful information transmission. This challenges a common assumption that leaders are solely responsible for outcomes. Although we note that slow information transmission through the entire ship's company may or may not be maladaptive, depending on context: in some cases efficient running of the ship might only require that information percolates through a sub-section of the crew. While we did not have the opportunity to directly test whether team performance is a function of information transmission, our results indirectly suggest that this may be the case. In future research, we hope to observe the role of the prestigious leader in directing information and mapping against a self-reported social network of advice donation, which is complimentary to the current advice-seeking networks.

In conclusion, prestige can be considered as a human analogue of dominance where status is achieved through the development of prestige rather than by force (Henrich and Gil-White, 2001). This places a lot of power in the hands of followers as "prestige givers" (Barkow et al., 1975). This process shapes the emergence of informal power structures within groups that are bound to abide by a formal hierarchical ranking structure and in the long term may also influence expectations associated with public roles (i.e., the transcendental social). Within a strictly hierarchical system, informally conferred prestige provides a flexible system that responds to perceived variation in capabilities and effectiveness of colleagues when faced with a shared task or objective.

The conclusions are of significance to social science disciplines engaged in environments where hierarchical top-down leadership is prevalent. Such environments would not necessarily be military but might also include the emergency services, the health sector, private companies (especially engineering) and the charity sector. The world of work is undergoing significant disruption at the current time in moving from command-and-control decision making (Industrial Age) to networked bottom-up influence (Information Age). These findings add to the body of knowledge concerning networked decision making in complex environments, explaining how prestige adds uniquely to the process.

\section{Data availability}

The datasets generated during and/or analysed during the current study are not publicly available due to the authors anticipating further use of the datasets. The data are available from the corresponding author on reasonable request.

Received: 6 September 2018 Accepted: 3 December 2018 Published online: 15 January 2019

\section{References}

Antonakis J, Day DV, Schyns B (2012) Leadership and individual differences: at the cusp of a renaissance. Leadersh Q 23(4):643-650

Asch SE (1948) The doctrine of suggestion, prestige and imitation in social psychology. Psychol Rev 55(5):250-276

Atkisson C, O’Brien MJ, Mesoudi A (2012) Adult learners in a novel environment use prestige-biased social learning. Evolut Psychol 10(3):519-537

Balkundi P, Kilduff M (2005) The ties that lead: a social network approach to leadership. Leadersh Q 16(6):941-961

Balkundi P, Kilduff M, Harrison DA (2011) Centrality and charisma: comparing how leader networks and attributions affect team performance. J Appl Psychol 96(6):1209-1222

Barkow JH et al. (1975) Prestige and culture: a biosocial interpretation. Curr Anthropol 16(4):553-572

Bird DW, Bliege R (2010) Competing to be leaderless: food sharing and magnanimity among martu aborigines.In: Vaughn KJ, Eerkens JW, Kantner J (eds) The evolution of leadership: transitions in decision making from small-scale to middle-range societies. School for Advanced Studies (SAR) Press, Santa Fe, pp 21-49

Bligh MC, Kohles JC, Pillai R (2011) Romancing leadership: past, present, and future. Leadersh Q 22:1058-1077

Bligh MC, Schyns B (2007) Leading questions: the romance lives on: contemporary issues surrounding the romance of leadership. Leadership 3(3):343-360

Bloch M (2008) Why religion is nothing special but is central. Philos Trans R Soc B 363:20552061

Boehm C (1993) Egalitarian behavior and reverse dominance. Curr Anthropol 34 (3):227-254

Boehm C (2001) Hierarchy in the forest. The evolution of Egalitarian behaviour. Harvard University Press, Cambridge 
Bolden R (2011) Distributed leadership in organizations: a review of theory and research. Int J Manag Rev 13(3):251-269

Bono JE, Anderson MH (2005) The advice and influence networks of transformational leaders. J Appl Psychol 90(6):1306-1314

Brass DJ, Burkhardt ME (1993) Potential power and power use: an investigation of structure. Acad Manag J 36(3):441-470

Cheng JT, Tracy JL, Foulsham T, Kingstone A, Henrich J (2013) Two ways to the top: evidence that dominance and prestige are distinct yet viable avenues to social rank and influence. J Pers Soc Psychol 104(1):103

Chudek M, Heller S, Birch S, Henrich J (2012) Prestige-biased cultural learning: bystander's differential attention to potential models influences children's learning. Evol Human Behav 33(1):46-56

Dinh JE, Lord RG (2012) Implications of dispositional and process views of traits for individual difference research in leadership. Leadersh Q 23(4):651-669

Edwards G (2014) Anthropological accounts of leadership : historical and geographical interpretations from indigenous cultures. Leadership 0(0):1-16

Grabo A, van Vugt M (2016) Charismatic leadership and the evolution of cooperation. Evol Hum Behav. 37(2016):399-406

Greenfield N, Kuznicki JT (1975) Implied competence, task complexity and imitative behaviour. J Social Psychol 95(2):251-261

Helbing D et al. (2015) Saving human lives: what complexity science and information systems can contribute. J Stat Phys 158(3):735-781

Henrich J, Boyd R (1998) The evolution of conformist transmission and the emergence of between-group differences. Evol Human Behav 19(4):215-241

Henrich J, Chudek M, Boyd R (2015) The big man mechanism: how prestige fosters cooperation and creates prosocial leaders. Phil Trans R Soc B 370 (1683):1-12

Henrich J, Gil-White FJ (2001) The evolution of prestige: freely conferred deference as a mechanism for enhancing the benefits of cultural transmission. Evol Human Behav 22(3):165-196

Hoppe B, Reinelt C (2010) Social network analysis and the evaluation of leadership networks. Leadersh Q 21(4):600-619

Jalili M, Perc M (2017) Information cascades in complex networks. J Complex Netw 5(5):665-693

Kakkar H, Sivanathan N (2017) When the appeal of a dominant leader is greater than a prestige leader. Proc Natl Acad Sci 114(26):6734-6739

Karp T (2013) Studying subtle acts of leadership. Leadership 9(1):3-22

King AJ, Johnson DDP, Van Vugt M (2009) The origins and evolution of leadership. Curr Biol 19(19):R911-R916

Larsson M, Lundholm SE (2010) Leadership as work-embedded influence: a microdiscursive analysis of an everyday interaction in a bank. Leadership 6 (2):159-184

McClurg SD, Lazer D (2014) Political networks. Soc Netw 36:1-4

Mehra A, Dixon AL, Brass DJ, Robertson B (2006) The social network ties of group leaders : implications for group performance and leader reputation. Organ Sci 17(1):64-79

Meindl JR (1995) The romance of leadership as a follower-centric theory: a social constructionist approach. Leadersh Q 6(3):329-341

Offord M, Gill R, Kendal J (2016) Leadership between decks : a synthesis and development of engagement and resistance theories of leadership based on evidence from practice in Royal Navy warships. Leadersh Org Dev J $37: 289-304$
Parker A, Gerbasi A, Porath CL (2013) The effects of de-energizing ties in organizations and how to manage them. Organ Dyn 42(2):110-118

Smith JM, Halgin DS, Kidwell-Lopez V, Labianca G, Brass DJ, Borgatti SP (2014) Power in politically charged networks. Soc Netw 36:162-176

Sparrowe RT, Liden RC, Wayne SJ, Kraimer ML (2001) Social networks and the performance of individuals and groups. Acad Manag J 44(2):316-325

Stogdill RM (1948) Personal factors associated with leadership: a survey of the literature. J Psychol 25(1):35-71

Van Vugt M (2009) Despotism, democracy, and the evolutionary dynamics of leadership and followership. Am Psychol 64(1): 54-56

Van Vugt M, Ahuja A (2010) Selected. Why some people lead, why others follow, and why it matters. Profile Books, London

Van Vugt M, Hogan R, Kaiser RB (2008) Leadership, followership, and evolution: some lessons from the past. Am Psychol 63(3):182-196

von Rueden C, Gurven M, Kaplan H, Stieglitz J (2014) Leadership in an egalitarian society. Hum Nat 25(4):538-566

Wasserman S, Faust K (1994) Social network analysis: methods and applications. Cambridge University Press, Cambridge

Zaccaro SJ (2007) Trait-based perspectives of leadership. Am Psychol 62(1):6-16

\section{Additional information}

The online version of this article (https://doi.org/10.1057/s41599-018-0211-8) contains supplementary material, which is available to authorised users.

Competing interests: The authors declare no competing interests.

Reprints and permission information is available online at http://www.nature.com/ reprints

Publisher's note: Springer Nature remains neutral with regard to jurisdictional claims in published maps and institutional affiliations.

(c) (i) Open Access This article is licensed under a Creative Common Attribution 4.0 International License, which permits use, sharing adaptation, distribution and reproduction in any medium or format, as long as you give appropriate credit to the original author(s) and the source, provide a link to the Creative Commons license, and indicate if changes were made. The images or other third party material in this article are included in the article's Creative Commons license, unles indicated otherwise in a credit line to the material. If material is not included in the article's Creative Commons license and your intended use is not permitted by statutory regulation or exceeds the permitted use, you will need to obtain permission directly from the copyright holder. To view a copy of this license, visit http://creativecommons.org/ licenses/by/4.0/.

(C) The Author(s) 2019 